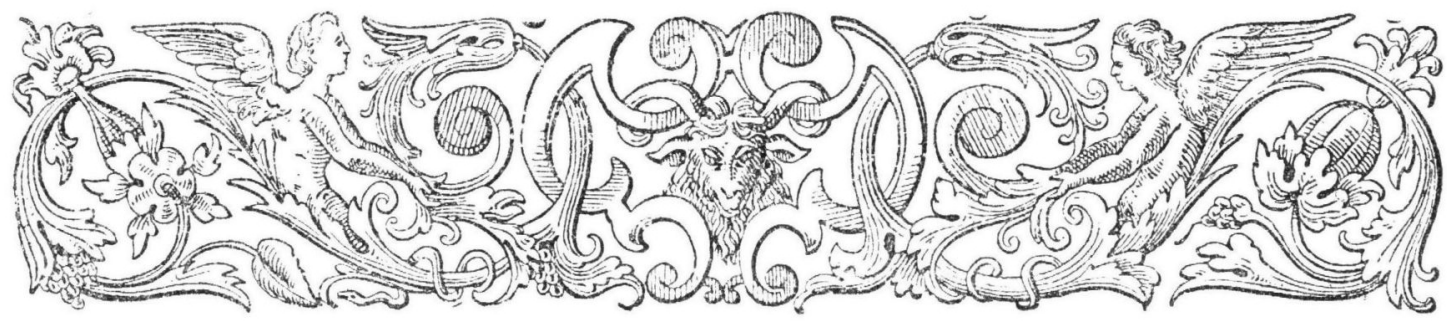

\title{
DE UTRECHTSCHE BEELDHOUWER COLYN DE NOLE EN ZIJN GESLACHT
}

DOOR

MR. S. MULLER FZ.

TRECHT moet in de middeleeuwen wel een centrum geweest zijn
van artistieke productie in Noord-Nederland: de stad met hare hier in de middeleenwen haren zetel zou hebben gehad. Het is waar, dat de herovering van den kostbaren reliekschrijn van St. Frederik de kunstkenners op het denkbecld heeft gebracht, dat het goudsmidsbedrijf te Utrecht in bijzondere eer zal zijn geweest. Ik geloof terecht; maar het is te betreuren, dat eerst de toevallige omstandigheid, dat de reliekschrijn te voorschijn kwam, de stad gerehabiliteerd heeft: immers reeds de middeleeuwsche bescheiden van het Smedengild schijnen op hetzelfde feit te wijzen ${ }^{1}$ ). Wie weet, of het met andere kunsten niet evenzoo gesteld is? De producten der Utrechtsche schilderkunst vóór SCOREL zijn grootendeels te niet gegaan of onkenbaar geworden; het Antwerpsche museum bevat nog eene merkwaardige schildering uit de St. Janskerk van 1363, en onder

1) Zie: OVervoorde en Joosting, De gilden van Utrecht. II p. 4I0, 4I4, 4I8, 422, 427 (ordonnantien van den raad voor de goudsmeden dd, I382(?), I433, I47 I, 1490 en I507).

Oxt-Holland 1907. 
de schatten van het Aartsbisschoppelijk museum zal wel een en ander schuilen, dat van hier afkomstig is. Maar met zekerheid weten wij daarvan niets. Toch hebben hier kunstenaars van naam geleefd en gewerkt. In de oude rekeningen ontmoeten wij telkens leden van de familie VAN SCHAYCK, die in de middeleeuwen zich blijkbaar heeft toegelegd op zeer verschillende takken van kunst en kunstnijverheid. Een van de leden dezer familie, EERst van SCHAYCK, schilderde in 1496 eene nieuwe tafel voor het hoogaltaar van den Don; zijne kunst werd dus voornaam genoeg geoordeeld, om te prijken op de allereerste plaats van het land, het hoogaltaar der kathedraal. Waar zijn de werken van dezen beroemden kunstenaar en van zijn artistiek geslacht gebleven? Het Nederlandsch museum bezit eene schilderij van eenen naamgenoot van den grooten EERST, afkomstig uit de St. Pieterskerk: denkelijk een kleinzoon, die niet in zijne schaduw staan kon. Men verhaalt, dat een ander altaarstuk van EERST VAN SCHAYCK uit Utrecht, dd. I600, berust te Lugo bij Ravenna ${ }^{1}$ ), en in het begin der $17^{\text {e eeuw }}$ droeg ook de Utrechtenaar GoERT VAN SCHAyCK eene prent der St. Pieterskerk te Rome op aall den gezant der Aartshertogen bij het pauselijk hof. Maar verder weten wij niets! Niet gelukkiger zijn de Utrechtsche beeldhouwers geweest, die toch reeds door den Dombouw alleen, die met tusschenpoozen de geheele latere helft der middelceuwen gevuld heeft, naar Utrecht gelokt moeten zijn. Ook onder hen moeten voorname kunstenaars gescholen hebben: de vier heiligenbeeldjes, die in het begin der I 5 e eeuw geplaatst werden in de St. Mariakerk, maken in het Stedelijk museum nog altijd de bewondering der kenners gaande. En niemand behoeft zich meer te verwonderen over de bijzondere distinctie der kapiteelen van het Heilige Graf in den Dom, sedert het gebleken is, dat de maker daarvan door den bisschop zelven werd waardig gekeurd, om als Dombouwmeester op te treden. Maar het werk der Utrechtsche beeldhouwers, door de beeldstormers gedecimeerd, is verwaarloosd, weggeworpen : hun werk is verdwenen, hunne namen zijn vergeten. En slechts bij zéér groote uitzondering kunnen de enkele overblijfselen der Utrechtsche kunst in verband gebracht worden met een der namen, die de oude rekeningen voor ons bewaard hebben.

In deze verdrietige omstandigheden moet het waarlijk een buitengewoon geluk heeten, dat ik over de in het hoofd genoemde beeldhouwersfamilie, die van de eerste helft der 16 e tot in de $I 7^{e}$ eeuw te Utrecht in eere was, niet alleen vrij wat verhalen kan, maar ook, althans van hare twee beroemdste leden, volkomen authentiek werk kan aanwijzen.

1) Eene teekening van Hercuies, door hem vervaardigd in 1594 , berust in het Prentkabine: te Darmstadt. (Vriendelijke mededeeling van den heer E. W. MoEs.) 
De stamvader van het geslacht is "COLYN DE NOLE beeltsnyder", die in de stedelijke rekening van $1553 / 4$ geboekt staat voor eene betaling, hem gedaan van "dat hy in deser stadts huysinge van Lichtenberch in den jare van 49 werkende (was) aen de beelden ende hoofden, die aldaer deur ordonnantie van Mr. JoHAN VAN SCHOERL, canonick van sunte Marie, gemaickt worden totter triumphe van de incompste van den prince van Hyspanie". Nogmaals komt hij voor in de rekening van $1552 / 3$, die mededeelt, dat hij "duer beveel van den oversten gemaict ende gelevert heeft gehadt een patroen, waernae hy presenteerde een schoersteenmantel te maicken in de nye camer van Cleyn Lichtenberch", - eene moeite, waarvoor hem bij raadsbesluit twee ponden werden toegelegd '). Van den bedoelden schoorsteenmantel is afkomstig een groot gebeeldhouwd fries, dat bewaard wordt in het Stedelijk museum. Maar ik durf niet te verzekeren, dat het ook naar Mr. CoLyN's teekening is bewerkt: immers eene post in de rekening van I 553/4 vermeldt, dat Mr. WILlEM VAN NoORT, „deser stadt metselryemeester", 42 pond ontving, "uuyt sake hy duer aenbestadinge van den burgermeesters ende anderde cameraer gemaickt ende geset heeft voer Lichtmisse anno 54, die schoersteenmantell mitten toebehoeren, staende in de nyewe camer van Cleyn Lichtenberch, genoemt nu der stadt wijnhuis" ${ }^{2}$. Naar het schijnt, is het dus de stadsarchitect VAN NOORT, die ook kort geleden den rijk gebeeldhouwden gevel van het stadhuis had opgetrokken, geweest, die het fries uitvoerde, wellicht naar de teekening van zijn concurrent, die toen met eene fooi van twee pond werd afgescheept. Maar al is dus de Utrechtsche schoorsteen denkelijk geen atithentiek werk van COLYN DE NOLE, ik kan ander werk van hem aanwijzen, dat, naar het mij voorkomt, rolkomen authentiek is en ook beroemder dan het Utrechtsche stuk. Immers reeds in 1543 had een Utrechtsche beeldhouwer, die zich Mr. COLyn vaN CAMERyck noemde, het prachtige schoorsteenfries gebeiteld ") in de Kampensche schepenzaal, dat wij allen kennen en dat hiernaast is afgebeeld. Dat wij hier denzelfden persoon voor ons hebben, die zich tien jaar later COLYN DE NOLE noemde, komt mij, wanneer wij overwegen, hoe ongemeen 's mans voornaam was, geheel niet twijfelachtig voor: het is geheel onaannemelijk, dat zich tezelfder tijd in eene niet zeer groote stad als Utrecht twee beroemde beeldhouwers met dienzelfden ongemeenen voornaam zullen bevonden hebben. En indien wij dit aannemen, dan werpt 's mans vroegste vermelding tevens een welkom licht op de geschiedenis van den kunstenaar: de Utrechtsche beeldhouwer met zijn Fransch-klinkenden naam was dus inderdaad

1) Kameraarsrekening. $1552 / 3$ fol. $58 \mathrm{vs}$.

2) Kameraarsrekening. $1553 / 4$ fol. 53 vs,

3) NANninga UitTERDijk, Kampen. p. 94. 
een Waal, afkomstig van de Fransche grens, uit Kamerijk ${ }^{1}$ ). In de kerkerekeningen wordt 's mans naam nog nu en dan genoemd: zoo reeds in het volgende jaar (1544/5) voor het snijlen van "aensichten ende dolmesgens" in de Buurkerk ${ }^{2}$ ). Maar het heeft weinig belang de lijst zijner kunstwerken samen te stellen, nu die toch verloren zijn.

Meer weten wij van zijn zoon, Utrechtsch beeldhouwer als hij. Zeer dikwijls wordt deze in de stukken vermeld, nu eens als Mr. JACOB CoLyn, dan weder als Mr. JACOB DE NOLE, slechts een enkele maal (in zijn grafschrift) voluit als "JACOB COLIN DE NOLE, beeltsnyder". In de lijst der Utrechtsche beeldsnijders van ${ }_{5} 69$ wordt JAECOP COLLYN ${ }^{3}$ ) vermeld als busmeester van het gild 4). In hetzelfde jaar was het "Mr. JACOB DE NOLE", die het nieuwe Sacramentshuis in de Buurkerk vervaardigde, nadat het oude zonder twijfcl door de beeldstormers was vernield ${ }^{5}$ ). En in 1580 , toen Utrechts aartsbisschop FREDERIK Schenck Van Tautenburg overleden was, was het weder Jacob Colijn, die op last van de executeurs van den prelat "een patroon van een sepulture" vervaardigde ${ }^{6}$ ). De tijdsomstandigheden hebben waarschijnlijk verhinderd, dit ontwerp uit te voeren; althans de kapel naast de sacristiedeur van den Dom, waar de prelaat begraven werd (thans een berghok in de kosterswoning) bevat zulk eene tombe niet $\left.^{7}\right)$. Doch voor deze teleurstelling worden wij op zeer bevredigende wijze schadeloos gesteld. Immers in VAN DER MONDE's Tijdschrift voor geschiedenis van Utrecht (1844 p. 87) staat vermeld, hoe de zonen van den heer van Amerongen, GofirT VAN REEDE, in I 608 kibbelende over de erfenis hunner ouders, verklaarden, dat "parthyen vader in zijn leven by eenen Mr. JACOB COLYN (hadde) doen houwen in steen sijn tombe ende ligchaem, verheven van der eerden, met sijn quartieren verchiert, alsoff hy een banderheer ware geweest, om 't Amerongen in de kerck gestelt te worden'. Heer GoERT overleed in 1585: vóór dien tijd is

\footnotetext{
1) Dat het dorp Kamerik in het sticht Utrecht zou bedoeld zijn (zooals inderdaad gegist is), is gelseel onaannemelijk, reeds wegens den Franschen naam van den kunstenaar.

2) DoDT, Archjef. VI p. 313 .

3) "JAECOP COLlyn off JAECOOP DYE OLLEY"; ik giste vroeger, of men hier verstaan mocht: Jacopo DI ORLEY, dus geïtalianiseerd volgens de toenmalige mode der artisten.

4) MULLEk, Schildersvereenigingen te Uirecht. p. 6I noot.

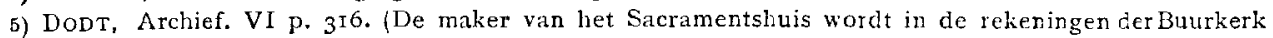
beurtelings Mr. Jacob Colyn en Mr. Jacob de Nole genoemd.)

6) DODT, Archief, IV p. 48.

7) In de $18 \mathrm{e}$ eeuw heeft men gemeend, deze tombe te herkennen in de anonyme zwart-toctsteenen tombe van bisschop GUY vaN Avesnes (overleden I317). KRAMm (Levens. I p. 258) verklaart bescheidenlijk, dat "het hem voorkomt, dat het geheel (dezer tombe) van vroegere kunsttype moet zijn," en acht het dan ook ,zijns inziens zeer gewaagd, deze tombe voor het werk van JACON COLYN te houden," O sancta simplicitas! De aarzeling is kostelijk, vooral in den mond van den kunsthistoricus KRAMM, die zich zoo bijzonder aanmatigerd kon uitlaten
} 


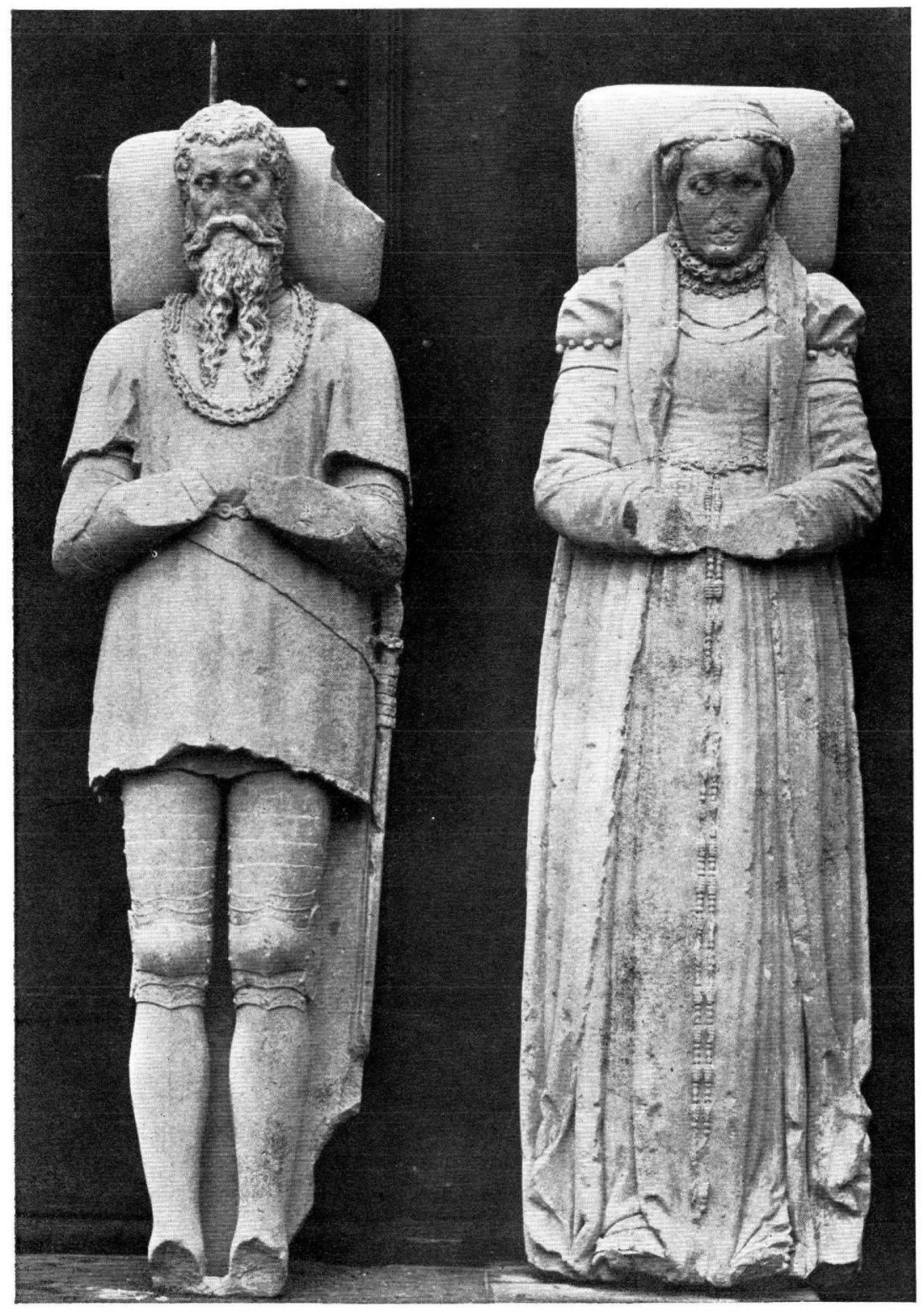

GRAFMONUMENT IN DE KERK TE AMERONGEN, (GOERT VAN REEDE EN ZIJNE ECHTGENOOTE) door JaCOB COLYN DE NOLE (ca 1580.) 
$$
\text { . }
$$ 


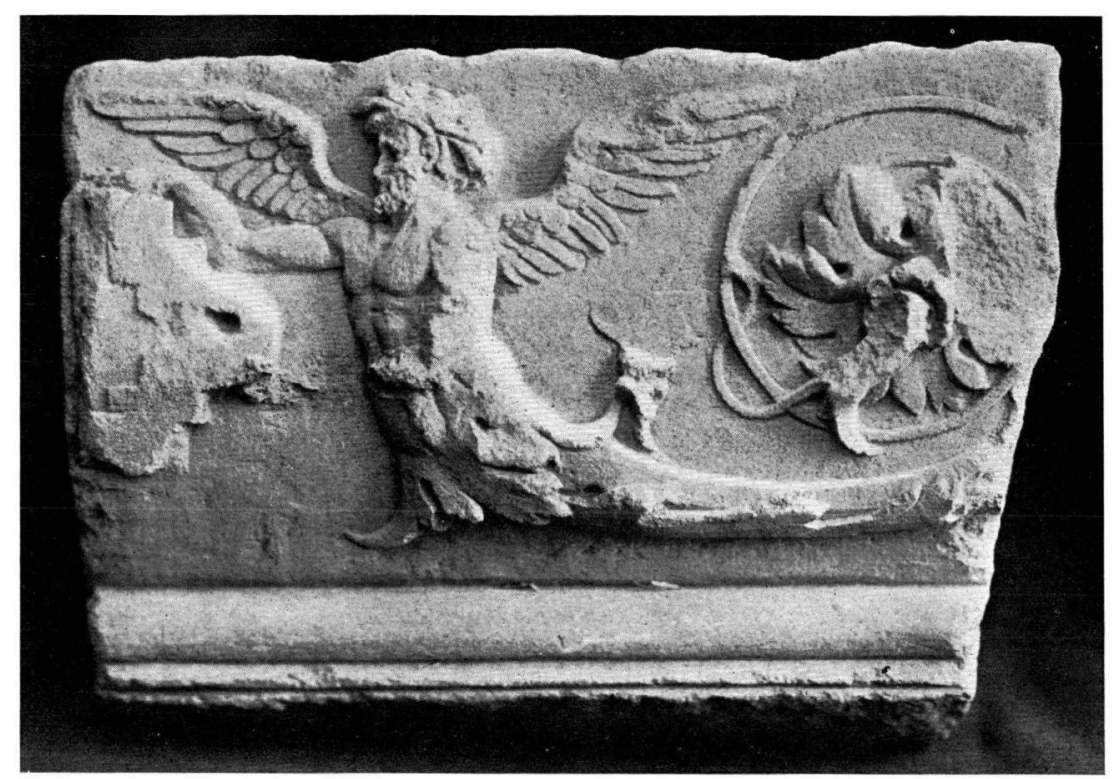

GRAFMONUMENT IN DE KERK TE AMERONGEN, (GOERT VAN REEDE EN ZIJNE ECHTGENOOTE) door Jacob COLIJN DE NOLE (ca 1580.) 

dus de tombe met zijn beeld gereed gemaakt; waarschijnlijk niet lang voor dien tijd, want de grafkelder der VAN REEDE'S lag voor op het koor, en het is niet aannemelijk, dat de heer van Amerongen een zoo omvangrijk monument, als de tombe moet geweest zijn, voor op het koor geplaatst zal hebben, zoolang er kans was, dat dit gevaarte den blik op het altaar zou beletten. Veeleer zal hij het koor, door de plaatsing van het groote monument in het midden daarvan, als grafkapel zijner familie hebben ingericht, toen, bij de invoering der hervorming in 1580 , het altaar vervallen was: tusschen 1580 en 1585 zal dus de graftombe tot stand gekomen zijn.

Ik zegr: tot stand gekomen, hoewel KRAMM, die de geschiedenis verhaalt, dit betwijfelt. Toch had hij niet behoeven te twijfelen: de tombe heeft inderdaad op het koor gestaan, en hij staat er zelfs sedert eenige dagen weder. KRAmM zelf zag in 1837 het beeld van den heer van Amerongen, aan welks identiteit hij echter twijfelde, -zeer ten onrechte, want de gelijkenis van den voorgestelden persoon is treffend ${ }^{1}$ ). En het daarbij behoorende beeld van 's mans echtgenoote, vrouw Geertruyd van Nyenrode (overleden in 1605), is later uit den grond weer te voorschijn gekomen met eenige andere fragmenten der tombe, die bewijzen dat het grafmonument zeer omvangrijk moet zijn geweest, voorzien van eene rijk versierde steencn overhuiving boven de op de tombe liggende beelden ${ }^{2}$ ).

Althans één groot werk van JACOB DE NOLE kunnen wij dus met zekerheid aanwijzen. Maar nu wij daaruit zijn stijl en behandelingswijze hebben leeren kennen, was het mogelijk, met voldoende zekerheid ook andere werken van zijne hand op te sporen.

Het Stedelijk museum van Utrecht bevat verschillende fraai in steen gebeeldhouwde schoorsteenfriezen, die wellicht de grootste schat der verzameling zijn. Toen ik met de Amerongsche fragmenten kennis maakte, trof mij aanstonds de groote overeenkomst in stijl en behandeling der beelden met vier dezer mij goed bekende stukken. En toen ik mijn gevoelen mededeelde aan den heer A. Prr, die wel de beste kenner onzer oude beeldhouwkunst is, bleek deze geheel van hetzelfde gevoelen: gesteund door zijne authoriteit, meen ik derhalve mijne gissing met vertrouwen te mogen publiceeren, zoo niet als absolute zekerheid dan toch als eene zéér aannemelijke attributie. Ik druk dus afbeeldingen van

1) Zie de geschilderde memorietafel an het echtpaar, blijkbaar bij de tombe behoorende, die thans op het kasteel Amerongen hangt. Nog duidelijker is de uiterst zeldzame zilveren penning op heer; GoERT van $555^{6}$, waarvan een exemplaar berust in het Stedelijk museum van Utrecht.

2) De beelden zijn thans weder in het koor geplaatst op een eenvoudig onderstuk, waarin ook de fragmenten zijn vastgemetseld. Het fraaiste der fragmenten van het fries der overhuiving wordt met de beelden hiernaast afgebeeld. 
de bedoelde schoorsteenfriezen hierbij af. De twee eerste friezen (met Salomo's recht en de geschiedenis van Suzanna), vroeger geplaatst in de rechtzaal van den bisschoppelijken officiaal en in de kapittelkamer van St. Marie, zijn merkwaardig, omdat, hoewel de bijzonderheden zeer verschillen, de voorstelling van beide stukken blijkbaar gevolgd is naar hetzelfde origineel ${ }^{1}$ ). De steen van het fries uit de kapittelkamer is helaas wat verweerd. Het derde fries is afkomstig uit een groot huis in de Hamburgerstraat, dat zeker vroeger behoord heeft bij de daarachter gelegen Johanniter-kommanderij van St. Catharijne: immers deze beide heiligen komen op het fries voor. Het was wellicht de woning van den balyer en kan dan mogelijk nog besteld zijn door den balyer WoUTER vaN BYLER, die in 1558 getuigenis gaf van zijn kunstzin door zich op eene prachtige bronzen penningplaat te doen vereeuwigen door den beroemden graveur STEPHANUS VAN HOLLANT 2). Zeker is dit niet: het jaar is voor JACOB DE NOLE vroeg genoeg maar het is toch mogelijk, want het vierde fries (fragment), atkomstig uit een huis in de Domsteeg, vertoont het wapenschild van een der vroegere bewoners, den kannunik ANtonie van Aemstel van Mrnden, die recds in 566 overleed.

Zoo is dus thans een belangrijk gedeelte van het oeuvre van JACOB DE NOLE met waarschijnlijkheid teruggevonden ${ }^{3}$ ). Over zijn leven kunnen wij nog ééne belangrijke bijzonderheid mededeeler: BUCILLIUS vermeldt in zijne aanteekeningen over de monumenten in de Utrechtsche kerken, dat in den noordmuur van de kerk der St. Paulus-abdij te zijnen tijde een grafmonument van Bentheimer steen te zien was, met portret en wapen en het volgende opschrift: "Hier leyt begraven JACOB Colin DE Nole, beeltsnider, die sterft $A^{o}$ I6O I den 8 Meert $\left.{ }^{4}\right) "$.

Doch met hem stierf zijne kunst te Utrecht niet uit. Reeds spoedig vinden wij dan in de bescheiden vermeld Willem JaCoBzoon Colyn, blijkbaar den zoon van JACOB DE NOLE, die zich JACOB COLyN noemde, en beeldhouwer als zijn vader. Ook hij was in het schrijven van zijn naam eenigszins onzeker: „WILLEM Colyn," ook "Willem Colyns" laat hij zich noemen en verwaarloost dus zijnen familienaam geheel, terwijl zijne zuster, die zich Elisabeth JACOBs DE NOLE

1) Dit was dan ook aanvankelijk de hoofdreden, waarom ik ook het ecrste fries (uit het officialaat) in de serie opnam: immers ik meende verschil in stijl te zien tusschen dit en de andere friezen. De heer PIT was echter van gevoelen, dat beide stukken aan hetzelfde atelier toegeschreven moesten worden. Bepaaldelijk bij het eerste fries constateerde hij groote orcrecrkomst met het werk van Germain PiLon.

2) Zie den penning afyebecld bij VAN Loon. I p. 26. (Een afgietsel is in het Stedelijk museum te Utrecht.

3) Niet onmogelijk moeten ook aan hetzelfde atelier toegeschreven norden de talrijke prachtige steenen schoorsteenfriezen met renaissance-ornamenten it hetzelfde museum; maar daar ons het ornament van JACOB DE NOLE niet door een voorbeeld bekend is, zou de attributie geheel onzeker zijn.

1) Buchelius, Monumenta. fol. 7 r vs. 


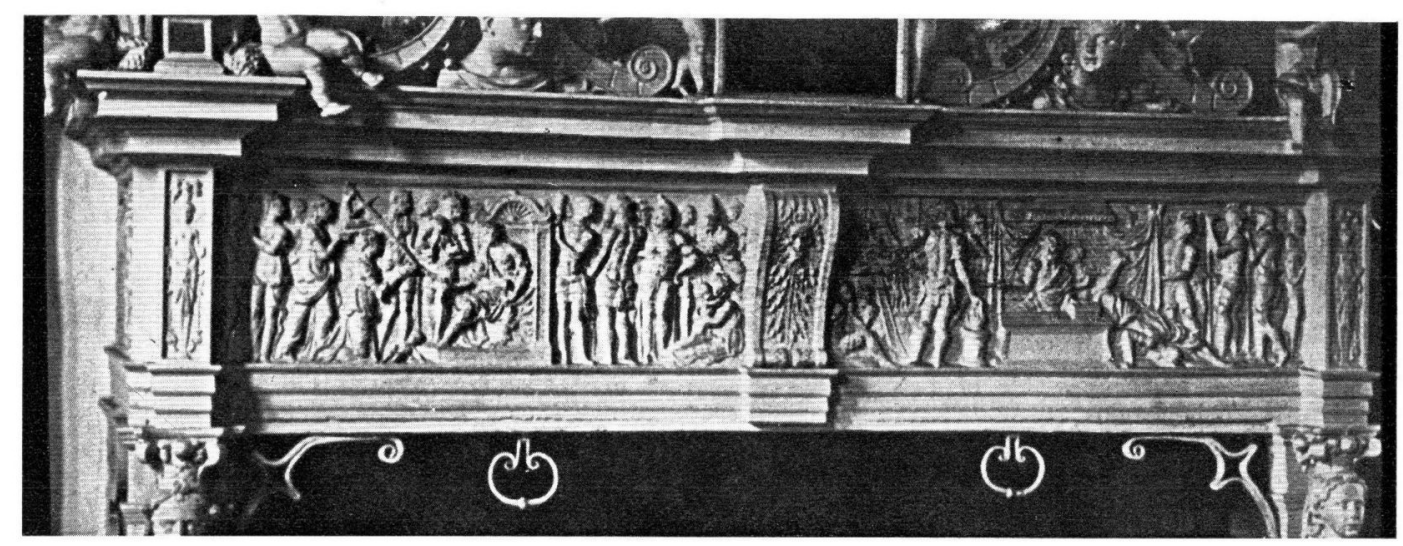

SCHOORSTEENFRIES TE KAMPEN,

doOr COLYN DE NOLE VAN KaMERIJK, 1543.

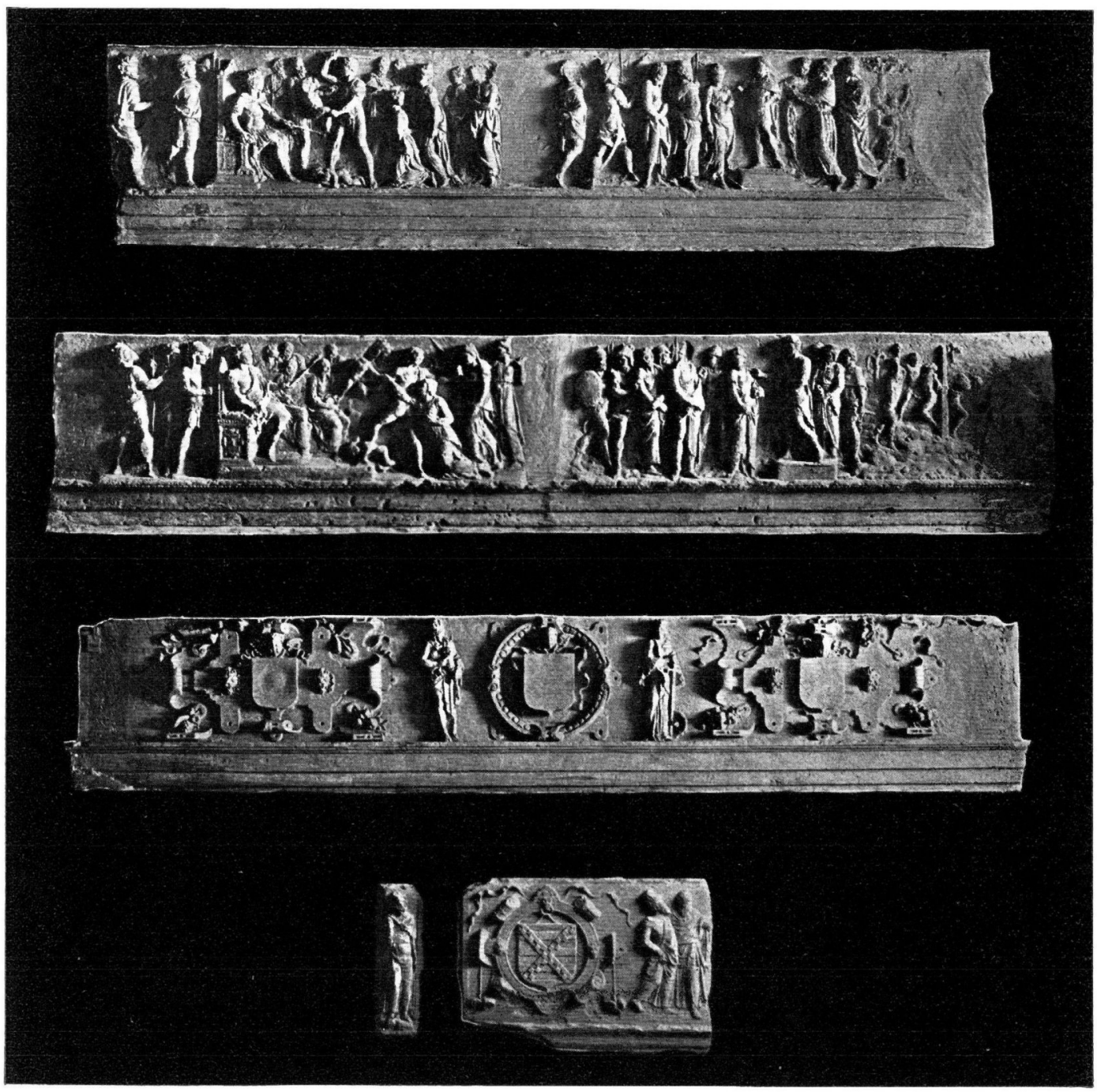

SCHOORSTEENFRIEZEN IN HET UTRECHTSCHE MUSEUM, toegeschreven aan JACOB COLYN DE NOLE. 
noemde, dien behouden had $\left.{ }^{1}\right)$. Reeds in 1604 komt hij voor als leverancier van eenig beeldhouwwerk aan het torentje van het stadhuis ${ }^{2}$ ). En ook in de rekening van I6I5/6 (fol. LIV) vinden wij twee posten van uitgaven aan, "WILLEM Coly steenhouwer" wegens leverantie van blauwen steen voor de Vischbrug en voor het houwen van twee steenen pilaren in het stadhuis. Van zijne positie bekomen wij een vrij wat minderen indruk dan van die van zijn vader: steenhouwer wordt hij herhaaldelijk genoemd. De fout lag toch niet aan hem, maar aan zijnen tijd: toen in $16 \mathrm{I}$ de Utrechtsche kunstenaars zich afscheidden van de zadelmakers en een afzonderlijk gild gingen vormen, wordt WILLEM JACOBZ. COLYN het eerst genoemd onder de „beelthouwers ende antijcksnyders." Hij was dus stellig nog beeldhouwer, en in 1620 bracht hij het dan ook tot deken van het gild naast den schilder ADaM WillaerTs.

Maar dat gild zelf was toen reeds bezig te ontaarden: de Reformatie had aan de beeldhouwerskunst haar eigenlijk terrein ontnomen: zoo waren de kunstenaars, onder den invloed der Renaissance, ontaard tot ,antijcqsnyders", artistieke meubelmakers, die in 1639 door de schilders uit hun gild werden gestooten. Willem COLYN beleefde deze schande van zijne collega's niet: in I620, het jaar zelf dat hem op den dekenzetel gebracht had, is hij overleden ${ }^{3}$ ).

Met hem stierf de bceldhouwersfamilie DE NOLE te Utrecht uit: als hij kinderen heeft nagelaten, dan hebben zij zich zeker gewijd aan andere beroepen, die in de $17 \mathrm{e}$ eeur in Nederland productiever waren. Dezelfde omstandigheden zullen allicht twee andere leden der familie reeds vroeger uit Utrecht verdreven hebben. Wij hebben gehoord, hoe de groote Utrechtsche beeldhouwer zich noemde JACOB COLYN DE NOLE; maar aangezien hij (zooals wel niet tegen. gesproken zal worden) de zoon was vail den beeldhouwer COLyN DE NOLE, had zijn naam eigenlijk moeten luiden: JACOB COLyns de Nole. Herinneren wij ons dit, dan is het zeer opmerhelijk, dat op het laatst der I6e ecuw te Antwerpen leefden twee beeldhouwers, die de namen droegen van Robre Colyns DE NOLE en Andreas Colyns de Nole, biijkbaar gevierd, door VAN Dijk geportretteerd en makers van verschillende kunstwerken (de hoofdaltaren in de Antwerpsche kathedraal en in de kerk te Lier, en standbeelden in de kerk van S. Carlo Borromeo

1) Zij was boch wel zeker eene dochter vin den beeldhouwer; want haar huwelijk met SYMoN WiTvELT, rector van het seminaric in de St. Paulus-abdij (Gifteboek der stad Rotterdam. I608 October 8, p. I64) gaf zeker aanleiding, dat de oude beeldhouwer zich begraven liet in de kerk, waarbij hij blijkbaar bij zijne dochter had ingewoond.

2) Kameraarsrekening. I603/4 fol. CII: „WILlem Colyns steenhouwer betaelt d'somme van drye ende twyntich ponden, uuyt sake hy volgende $d$ aenbestadinge hem gedaen gemaeckt heeft een fondespits ende dacronder het stadtswapen, ende 't selve gestelt heeft op der Stadthuysinge op de plaets onder hethorologium alsoock voorde steen, by hem daertoe gelevert, dus alhyer, blijckende als vooren, dvoors. 23 pont."

3) MULLER, Schildersvereenigingen. p. 128 noot 2. 
en in de kathedraal te Antwerpen), bovendien leveranciers van aartshertog ERnst en van Albertus en ISABELla ${ }^{1}$ ). Het ligt voor de hand aan te nemen, dat deze beide beroemde Antwerpsche kunstenaars jongere zonen zullen geweest zijn van den Utrechtschen beeldhouwer COLYN DE NOLE, die in het zuiden het werk gezocht hebben, dat zij in het hervormde Utrecht niet meer vonden. Is dit juist, (en ik houd het voor uiterst waarschijnlijk), dan kan de leeftijd der gebroeders daartegen niet als overwegend bezwaar worden aangevoerd; immers ROBERT kwam in I594, wellicht niet jeugdig meer, in het Antwerpsche St. Lucasgild en overleed in 1636 ; reeds KRAMM heeft opgemerkt, dat zijn broeder en medewerker ANDREAS niet veel jonger dan hij ban zijn geweest. Belangrijk zou het zijn na te gaan, of het werk der Antwerpsche broeders nog eenige sporen vertoont van hunne herkomst uit het noorden ${ }^{2}$ ).

1) Zie: ImMerzeel, Levens. II p. 265. - KRAmm, Levens. IV p. 1203

2) In dit verband is ook nog te noemen ALEXANDER Colin, geboren in 1527 te Mechelen en overleden na I60I: hij is de maker van het beroemde praalgraf van keizer MAximiliaAN te Innsbruck. Ik zie echter geen reden, om hem met COLy ve NOLE in verband te brengen.

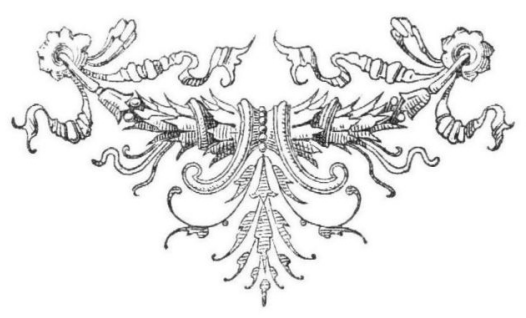

